\title{
Active smoking and exposure to secondhand smoke and their relationship to depressive symptoms in the Korea national health and nutrition examination survey (KNHANES)
}

Sun Jae Jung ${ }^{1}$, Aesun Shin $^{2}$ and Daehee Kang ${ }^{1,2,3^{*}}$

\begin{abstract}
Background: The relationship between tobacco smoking, including secondhand smoking, and depression has been assessed. The purpose of this study was to evaluate the association between secondhand smoking among current, former and never smokers and depressive symptoms. For secondhand smoking, gender differences and sources of exposure were examined.
\end{abstract}

Methods: Data from 34,693 participants from the fourth and fifth Korean Health and Nutritional Examination Survey (2007-2012) were analyzed in 2014. Self-reported exposure to active (current, former or never) and secondhand smoking and depressive symptoms experienced during the past year were analyzed using logistic regression. The dose-response relationship between duration of secondhand smoke exposure and depression was assessed with stratification by gender and sources of exposure (at home only, at the workplace only or both).

Results: Regardless of their smoking status, all women who had secondhand smoke exposure at home reported more depressive symptoms than non-smoking women without any exposure to secondhand cigarette smoking (OR 1.43, $95 \%$ Cl 1.04-1.96 for current smokers; OR 2.32, 95 \% Cl 1.04-5.16 for former smokers; OR 1.25, 95 \% Cl 1.08-1.43 for never smokers). There was also a significant dose-response pattern ( $p$-trend $<0.001$ ) for the duration of secondhand smoke exposure at home among women. No significant association was found between smoking and depressive symptoms in men.

Conclusions: There was a significant association between secondhand smoke exposure at home and depressive symptoms in women. Secondhand smoke exposure at home was associated with depressive symptoms in a doseresponse manner.

Keywords: Cigarette smoking, Secondhand smoke, Depressive symptoms

\section{Background}

Smoking tobacco is well known to be harmful to overall health and is a major cause of death and disease. In Korea, $30.8 \%$ and $5.7 \%$ of deaths among men and women, respectively, have been attributed to active smoking [1]. According to one study, 8,284 people died of either lung cancer or ischemic heart disease due to

\footnotetext{
* Correspondence: dhkang@snu.ac.kr

'Department of Biomedical Science, Seoul National University College of Medicine, Seoul, South Korea

${ }^{2}$ Department of Preventive Medicine, Seoul National University College of Medicine, Seoul, South Korea

Full list of author information is available at the end of the article
}

current smoking and an additional 422 non-smokers died of the same diseases due to secondhand smoke (SHS) in 2010 [2]. Furthermore, approximately 100 billion cigarettes are sold annually in Korea; thus, according to World Health Organization (WHO) data, Korea is the 8th largest cigarette market [3]. The smoking rate among men and women was approximately $40 \%$ and $5 \%$, respectively, in 2011 [4]. Similar to other countries [5], several public policies have been established to protect the general population from SHS in Korea since 1995 [6]. The policies mainly focus on exposure in open public places such as workplaces, large theaters, 
hospitals, schools, auditoria, gymnasia and public transportation. These policies successfully led to a decrease in the prevalence of smoking among men (46.7\% in 2007 and $44.9 \%$ in 2010) [7]. However, the prevalence of smoking among women increased during the same period [8]. In 2011, approximately $55.2 \%$ of men and $37.2 \%$ of women who participated in the Korean National Health and Nutritional Examination Survey (KNHANES) reported that they were exposed to indoor workplace SHS, whereas $16.7 \%$ of men and $4.9 \%$ of women were exposed to SHS at home [9]. Recently, there has been a growing number of debates on banning smoking inside apartments in Korea. Furthermore, there is also increased awareness of the positive effects of smoking bans at home [10]. Studies have shown inconsistent results concerning the potential factors associated with SHS exposure [11, 12].

While the harmful effects of smoking have frequently been discussed in relation to overall mortality of other diseases such as cancer, some studies have also begun to focus on the adverse effects of active smoking on mental health, presenting the harmful effect of active smoking on depression $[13,14]$. Nevertheless, the results regarding SHS and depression are controversial $[15,16]$.

In Korea, the prevalence of depression, measured using the Center for Epidemiological Studies-Depression Scale (CES-D), was $23.1 \%$ and $27.4 \%$ among men and women, respectively [17]. Koreans who immigrated to the U.S. showed approximately $30.0 \%$ to $36.0 \%$ prevalence of depression, as measured by the CES-D [18, 19]; these rates were relatively high compared to the general American population (3-21\%) [20-22].

Many studies have evaluated the bidirectional relationship between current smoking and depressive symptoms, but fewer studies have examined the association between SHS and depression. One study on Japanese workers showed a positive association between SHS exposure and prevalence of depression [23]. Depression is twice as prevalent in females [24], and there may be different etiologies for depression in men and women. In addition, it has been reported that gender significantly modifies the association between smoking and depression; the prevalence of depression tends to be higher among female current smokers compared to female former or never smokers, whereas the prevalence among male current smokers and never smokers does not differ [25]. In addition, among non-smokers, women are more frequently exposed to SHS at home than men $[9,26]$. The source of SHS exposure should also be distinguished to assess the different association between SHS and depression. Another study conducted in Korea assessed the association between SHS and depressive symptoms in middle and high school students using a school-based survey. This study showed a dose-dependent association between SHS and depression [15, 27].

The purpose of the current study was to explore the association of smoking status (current, former or never) and SHS exposure with depressive symptoms and to assess the possible dose-response relationship between SHS exposure duration and depressive symptoms stratified by gender using information from a nationally representative survey in Korea.

\section{Methods \\ Study participants}

Data were drawn from the fourth and fifth Korean Health and Nutritional Examination Survey IV-V (KNHANES 2007-2012). KHNANES provides nationally representative data by selecting participants from the non-institutional population in South Korea using a complex stratified multistage probability-clustered sampling design [28]. Since 2007, surveys have been conducted annually using in-person interviews and a multi-stage clustered probability design. More information about the sampled participants can be found elsewhere [28]. From a total of 50,405 participants in KNHANES 2007-2012, data from 34,693 respondents over the age of 18 years and without missing information on smoking and symptoms of depressive and stress were used in the final analysis (Fig. 1).

\section{Measures}

All the interviews regarding socioeconomic factors and self-perceived health status were conducted by trained interviewers using structured questionnaires. Smoking status, alcohol consumption, perceived stress and depressive symptoms were all self-reported. To ascertain smoking status, participants were asked the following questions: "How many cigarettes have you smoked in total?" and "Do you currently smoke?". If the participants answered that they have smoked 100 cigarettes or more in their lifetime and that they smoke currently, there were categorized as "current smokers". If participants answered that they do not smoke currently but that they had smoked 100 cigarettes or more, they were classified as "former smokers". People were labeled as "never smokers" if they reported that they have smoked less than 100 cigarettes in the lifetime. Those who answered that they either smoked every day or occasionally were additionally asked how many cigarettes they consumed per day or how many days they smoked in the previous month. To assess the presence and the amount of workplace SHS exposure, all participants were asked, "How many hours per day are you exposed to other people's cigarette smoke in the workplace?" Participants were also asked if there is any other family member who 


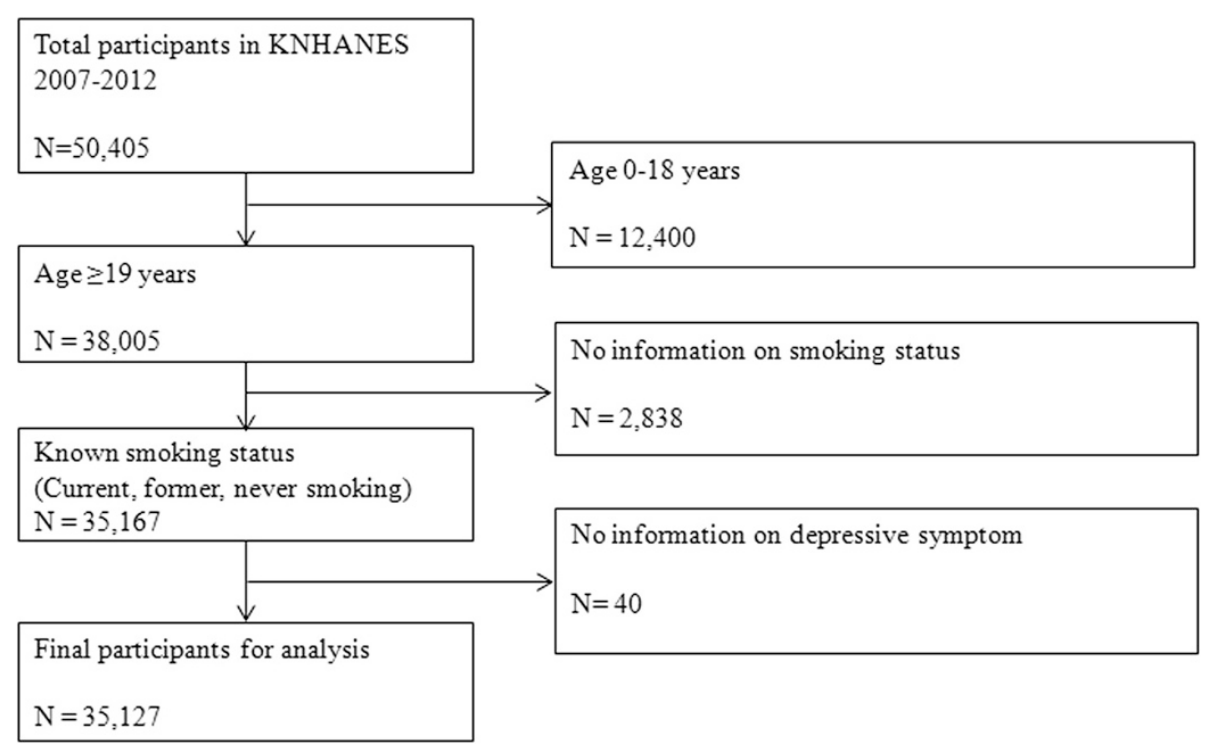

Fig. 1 Data management flow (KNHANES 2007-2012)

smokes inside the house everyday other than themselves. If the participants answered "yes", they were asked the number of smokers other than themselves and the total hours per day of exposure to cigarette smoke. For both exposures, participants reported how many hours they were exposed by checking "no exposure", "exposed $<1 \mathrm{~h} /$ day" and "exposed $\geq 1 \mathrm{~h} /$ day". Depressive symptoms were assessed with the following question: "In the past year, have you felt extremely sorrowful or despair for more than 2 weeks?". The participants answered this question as "yes" or "no". This questionnaire was used to identify people with depressive mood from the beginning of KNHANES (1998). It is widely used to measure participants with clinical or subclinical depressive symptoms, which are expected to be a proxy for depressive disorder $[29,30]$. In addition, people were asked whether they ever had a diagnosis of clinical depression confirmed by physicians. Participants who answered "yes" had to report the age at their first diagnosis of depression. The participants' level of stress was asked by the following question: "During ordinary days, how much do you feel stressed?: very much, moderate, somewhat or not at all." To measure employment status, participants were asked about their current financial activity. Excluding the people who answered that they are not financially active or they are unemployed, have no intention to work or do not have the ability to work, participants were asked which of the following employment types applied to them: wage employee, independent business owner or worker in the family business. The Alcohol Use Disorders Identification Test (AUDIT) scores were classified following the conventional risk level cut-off $(-7 / 8-15 /$ 16-19/20-40) [31]. Self-rated health was measured by asking the participants the following question: "What do you think about your current health status: very good, good, normal, bad or very bad?".

\section{Statistical analysis}

As data from KNHANES were derived from multistage complex probability sampling to represent the entire South Korean population, population weightings were applied in the analyses. The PROC SURVEY procedure in SAS 9.3 (SAS Institute Inc., Cary, NC, USA) was used to apply stratification, primary sampling units and population weights. Because the data were integrated from 2007 to 2012, we calculated the separated integrating weight for each year in proportion to that year's response rate. Continuous variables were categorized by order. The exposure categories included four SHS statuses (Never exposed to SHS, SHS exposure at home only, SHS exposure at workplace only and SHS exposure in both places) and active smoking (Current smoker, former smoker and never smoker). Never smokers who answered that they were not to exposed to any SHS served as the reference groups for both genders. Age was grouped as 19-39 years, 40-59 years and 60 years and older. Body mass index (BMI) was categorized following the WHO criteria for Asians [32]. The participants selected for analysis were those who did not have missing values on the main exposure (smoking status) and outcome variables (depressive symptoms), and the missing values on other variables were coded separately and included in the models to calculate odds ratios. To describe the distribution of baseline characteristics, the PROC SURVEYFREQ procedure was applied. The likelihood ratio test was conducted to evaluate possible 
covariates in the model. Each possible covariate was added to the model, and -2 Log likelihood was compared with previous model. If the difference was statistically significant in $\chi^{2}$-distribution (degree of freedom $=1$, $p$-value $<0.05)$, the variable was selected as an adjustment variable. Age, marital status, education, employment status, self-reported stress, self-rated health and alcohol consumption (measured as the AUDIT score) and past diagnosis of depression by physicians were selected as the final covariates in the model. After stratifying for gender, adjusted odds ratio for depression were calculated by 12 categories $(3 \times 4)$ regarding 3 groups for smoking status (current, former, never smoker) and 4 groups for exposure to SHS (No exposure to SHS, SHS at home only, SHS at workplace only, SHS at both home and workplace) using PROC SURVEYLOGISTIC. For those who had never smoked, SHS exposure in the workplace and at home was grouped by dose of exposure (no exposure, $<1$ or $\geq 1 \mathrm{~h} /$ day). Trend tests were performed by using the order of categories. Additionally, as participants had information concerning whether they had been diagnosed with clinical depression by physicians, we conducted a sensitivity analysis to avoid selection bias by excluding the participants who reported a history of depression diagnosed by physicians. All statistical analysis were conducted with SAS 9.3; the significance level was set at $p<0.05$. All analyses were conducted in 2014.

\section{Ethics}

All KNHANES participants provided written consent to participate in the survey and for their personal data to be used. This study, which conducted analyses with publicly open data, was approved by the Institutional Review Board of the Seoul National University Hospital, Korea (IRB No. 1408-068-602).

\section{Results}

Baseline characteristics of the study population

As shown in Table 1, there was a total of 35,127 participants in this study, of whom $35.7 \%$ were current smokers, $10.8 \%$ were former smokers and $53.5 \%$ had never smoked. Among the 14,886 men, the weighted percentages of current and former smokers and those who never smoked were $62.0 \%, 18.2 \%$ and $19.8 \%$, respectively. Among the 20,241 women, the weighted percentages of current and former smokers and those who never smoked were $10.2 \%, 3.6 \%$ and $86.3 \%$, respectively. The weighted percentages of people who had any exposure to SHS were $53.4 \%$ among men and $42.7 \%$ among women. Among the men, current smokers were slightly older than those who had never smoked (14.4\% compared to $13.5 \%$ were aged $\geq 60$ years), but among the women, current smokers were younger than those who had never smoked (57.5\% compared to $36.6 \%$ were aged 19-39 years). Among never smokers, a greater percentage of the men attained education for 12 years or more compared to women $(40.7 \%$ of men and $27.4 \%$ of women attained $\geq 12$ years of education). Women who had never smoked were less likely to report no financial activity compared to current female smokers (never smoked, $51.0 \%$, compared to current smoker, $52.6 \%$ ), whereas men with no financial activity were more likely to have never smoked (29.3\% compared to $20.5 \%$ of current smokers). Women who had never smoked had a lower BMI than those who smoked. There was a greater proportion of both male and female smokers than nonsmokers among the participants who reported alcohol consumption ("ever drank") (97.5\% of men and $92.9 \%$ of women) and higher self-reported stress among current smokers compared to those who never smoked. Similarly, participants who never smoked reported better health status than smokers (Data not shown). A total of 1,468 (9.9 \%) men and 3,658 (18.1 \%) women reported depressive symptoms.

\section{Association between smoking and depressive symptoms}

In the multivariate analyses, stratified by gender (Table 2), there was no significant association between smoking and depression in men. However, women who answered that they were exposed to SHS only at home showed significantly increased ORs on depression regardless of their active smoking status (Current, former or never smokers): Odds ratio (OR) 1.43, 95 \% CI 1.04-1.96 for current smokers, OR 2.32, 95 \% CI 1.04-5.16 for former smokers and OR 1.25, $95 \%$ CI 1.08-1.43 for never smokers. In addition, among women, current smoker status combined with exposure to SHS both at home and workplace was marginally associated with elevated depressive symptoms (OR 1.57, 95 \% CI 0.96-2.55). Likewise, for women who had never smoked, SHS exposure both at home and the workplace increased their OR of depressive symptoms by 12 \% (OR 1.22, 95 \% CI 0.99-1.404). In contrast, SHS exposure at the workplace did not show statistically significant associations with the likelihood of elevated depressive symptoms for any smoking groups.

\section{Dose-response relationship between SHS and depressive symptoms}

Among men who had never smoked and had occupational exposure to SHS, exposure for $\geq 1 \mathrm{~h}$ /day was associated with marginally increased odds of depression (OR 1.23, $95 \%$ CI 0.97-1.54). Nevertheless, the test for a linear trend between SHS and depressive symptoms was not significant. The OR pattern was similar among nonsmoking men who had only been exposed to SHS at home; however, none of the results reached statistical significance. In contrast, the results for women differed. 
Table 1 Baseline characteristics of participants by depression status in KNHANES 2007-2012

\begin{tabular}{|c|c|c|c|c|c|c|}
\hline \multicolumn{7}{|l|}{$(N=$, weighted $N=)$} \\
\hline & \multicolumn{2}{|c|}{ Men $(N=14,886$, weighted $N=18,449,986)$} & \multirow[b]{2}{*}{$P$-value } & \multicolumn{2}{|c|}{ Women $(N=20,241$, weighted $N=18,929,457)$} & \multirow[b]{2}{*}{$P$-value } \\
\hline & $\begin{array}{l}\text { depression }(-) \\
(N=13,418) \text { (Weighted } \\
N=16,715,177)\end{array}$ & $\begin{array}{l}\text { depression (+) } \\
(N=1,468) \text { (Weighted } \\
N=1,734,808)\end{array}$ & & $\begin{array}{l}\text { depression }(-) \\
(N=16,583) \text { (Weighted } \\
N=15,575,753)\end{array}$ & $\begin{array}{l}\text { depression } \\
(+)(N=3,658) \text { (Weighted } \\
N=3,353,704)\end{array}$ & \\
\hline General factors & Weighted \% & Weighted \% & & Weighted \% & Weighted \% & \\
\hline Smoking status & & & 0.015 & & & $<0.001$ \\
\hline \multicolumn{7}{|l|}{ Current smoker } \\
\hline Exposed to SHS & 34.9 & 37.8 & & 4.9 & 9.1 & \\
\hline Not Exposed to SHS & 26.6 & 29.8 & & 4.2 & 6.4 & \\
\hline \multicolumn{7}{|l|}{ Former smoker } \\
\hline Exposed to SHS & 8.4 & 7.6 & & 1.3 & 2.1 & \\
\hline Not Exposed to SHS & 10.0 & 8.7 & & 2 & 2.3 & \\
\hline \multicolumn{7}{|l|}{ Never smoker } \\
\hline Exposed to SHS & 9.6 & 8.0 & & 31.5 & 31.5 & \\
\hline Not Exposed to SHS & 10.6 & 8.1 & & 56.1 & 48.6 & \\
\hline Age & & & $<0.001$ & & & $<0.001$ \\
\hline 19-39 & 43.7 & 36.2 & & 41.0 & 33.0 & \\
\hline $40-59$ & 39.8 & 43.3 & & 38.5 & 39.2 & \\
\hline$\geq 60$ & 16.6 & 20.5 & & 20.5 & 27.8 & \\
\hline Marital status & & & $<0.001$ & & & $<0.001$ \\
\hline Never married & 25.7 & 25.5 & & 17.5 & 15.0 & \\
\hline Married-living with partner & 70.3 & 64.4 & & 67.7 & 61.0 & \\
\hline Married-others & 4.0 & 10.1 & & 14.8 & 24.0 & \\
\hline Education attainment & & & $<0.001$ & & & $<0.001$ \\
\hline$<6$ years & 12.0 & 19.7 & & 24.1 & 35.4 & \\
\hline $6-8$ years & 10.0 & 13.4 & & 9.8 & 11.7 & \\
\hline $9-11$ years & 42.2 & 41.2 & & 37.7 & 33.5 & \\
\hline$\geq 12$ years & 35.9 & 25.7 & & 28.5 & 19.4 & \\
\hline Employment status & & & $<0.001$ & & & 0.002 \\
\hline Wage working & 49.4 & 38.3 & & 32.4 & 28.7 & \\
\hline Self-supporting & 26.9 & 29.1 & & 11.1 & 10.8 & \\
\hline House-employed & 1.6 & 2.5 & & 5.9 & 5.8 & \\
\hline No financial activity & 22.0 & 30.0 & & 20.6 & 54.6 & \\
\hline Number of family members & & & $<0.001$ & & & $<0.001$ \\
\hline Living alone & 4.9 & 7.7 & & 6.2 & 9.3 & \\
\hline Living with one family member & 19.4 & 20.5 & & 19.2 & 22.9 & \\
\hline $\begin{array}{l}\text { Living with two family } \\
\text { members }\end{array}$ & 26.8 & 26.8 & & 24.6 & 25.9 & \\
\hline Living with $\geq 3$ family members & 48.8 & 45.0 & & 49.9 & 41.9 & \\
\hline Body mass index (kg/m2) & & & 0.5 & & & 0.018 \\
\hline$<18.5$ & 3.0 & 3.5 & & 6.7 & 6.5 & \\
\hline $18.5-22.9$ & 34.9 & 36.1 & & 45.1 & 42.7 & \\
\hline
\end{tabular}


Table 1 Baseline characteristics of participants by depression status in KNHANES 2007-2012 (Continued)

\begin{tabular}{|c|c|c|c|c|c|c|}
\hline $23-24.9$ & 25.6 & 26.1 & & 20.8 & 20.8 & \\
\hline $25-29.9$ & 32.2 & 31.1 & & 23.2 & 24.5 & \\
\hline$\geq 30$ & 4.2 & 3.2 & & 4.2 & 5.5 & \\
\hline $\begin{array}{l}\text { Alcohol dependence by AUDIT } \\
\text { score }\end{array}$ & & & $<0.001$ & & & $<0.001$ \\
\hline 0-7 (Normal) & 44.2 & 39.6 & & 84.1 & 76.1 & \\
\hline 8-15 (Mild dependence) & 34.2 & 26.7 & & 12.6 & 15.6 & \\
\hline 16-19 (Moderate dependence) & 11.2 & 12.9 & & 1.6 & 3.8 & \\
\hline 20-40 (Severe dependence) & 10.5 & 20.8 & & 1.7 & 4.5 & \\
\hline Self-reported stress & & & $<0.001$ & & & $<0.001$ \\
\hline Very high & 2.7 & 16.4 & & 3.0 & 17.5 & \\
\hline High & 19.5 & 42.0 & & 21.5 & 44.7 & \\
\hline Moderate & 61.7 & 37.5 & & 60.4 & 32.7 & \\
\hline Little & 16.0 & 4.2 & & 15.1 & 5.0 & \\
\hline Self-reported health status & & & $<0.001$ & & & $<0.001$ \\
\hline Very good & 5.9 & 3.8 & & 4.0 & 2.4 & \\
\hline Good & 37.3 & 21.5 & & 31.8 & 19.3 & \\
\hline Normal & 43.8 & 41.4 & & 44.8 & 38.6 & \\
\hline Bad & 11.7 & 27.2 & & 16.7 & 30.4 & \\
\hline Very bad & 1.3 & 6.1 & & 2.7 & 9.3 & \\
\hline
\end{tabular}

Among non-smoking women, SHS exposure of $\geq 1 \mathrm{~h} /$ day both in the workplace and at home was significantly associated with increased odds of depressive symptoms (workplace: OR 1.32, 95 \% CI 1.06-1.64; home: OR 1.71, $95 \%$ CI 1.34-2.18). A longer duration of daily SHS exposure at home increased ORs ( $p$-trend for home exposure, <0.001) (Table 3).

\section{Sensitivity analysis}

In our data, 246 men and 1,124 women reported having a prior diagnosis of clinical depression confirmed by physicians. We excluded these participants and recalculated the odds ratios for the association between each smoking status and depressive symptoms. Similar to the prior analysis including the participants with prior depression, only women showed a significantly increased odds ratio on depression with SHS at home only (OR 1.53, 95 \% CI 1.09-2.15 for current smokers, OR 1.21, $95 \%$ CI 1.04-1.40 for never smokers). Female former smokers who were exposed to SHS at home showed marginally increased OR on depression (OR 2.23, $95 \%$ CI 0.95-5.28).

Likewise, we re-conducted the analysis using different exposure doses in workplace and at home while excluding participants with prior depression. Overall, results of the original data and the data with exclusion were very similar. There was no significant result among men. In contrast, women who were exposed to SHS in the workplace or at the home had significantly greater odds of depressive symptoms than those with less exposure ( $<1 \mathrm{~h}$ per day) (OR 1.38, $95 \%$ CI 1.10-1.73 for women who had SHS exposure at the workplace and OR 1.69, $95 \%$ CI 1.31-2.17 for women who had SHS exposure at home). Women who had SHS exposure at home showed a significant trend ( $p$-trend <0.001) (data not shown).

\section{Discussion}

This study evaluated the association between adults' SHS and depressive symptoms by the exposure source in a nationally representative dataset. In this study, we found a significant association between active or secondhand smoking and depressive symptoms in women. Women who were exposed to SHS at home showed a stronger dose-response relationship than those exposed at the workplace. It is interesting that only women showed a significant trend in the dose-response relationship between SHS duration and depressive symptoms at home.

The association between SHS and depressive symptoms has been assessed in several studies [23, 27, 33-35]. In a study conducted with non-smoking Korean adolescents, exposure to SHS increased the likelihood of depressive symptoms in both genders after adjustment [33]. 
Table 2 Association between smoking status (current, former and secondhand smoke (SHS)) and depressive symptoms

\begin{tabular}{|c|c|c|c|}
\hline \multirow[t]{3}{*}{ Smoking status } & \multicolumn{3}{|l|}{ Depression } \\
\hline & \multirow{2}{*}{$\begin{array}{l}\text { No } \\
N \text { (Weighted \%) }\end{array}$} & Yes & $\mathrm{OR}^{\mathrm{a}}(95 \% \mathrm{Cl})$ \\
\hline & & $N$ (Weighted \%) & \\
\hline \multicolumn{4}{|l|}{ Men } \\
\hline \multicolumn{4}{|l|}{ Smoking status } \\
\hline \multicolumn{4}{|l|}{ Current } \\
\hline No exposure to SHS & $3,859(26.6)$ & $470(29.8)$ & $1.15(0.86-1.55)$ \\
\hline SHS at home only & $526(3.7)$ & $85(6.5)$ & $1.42(0.92-2.18)$ \\
\hline SHS at workplace only & $3,120(26.2)$ & $339(25.4)$ & $1.13(0.83-1.54)$ \\
\hline SHS at both home and workplace & $525(5.0)$ & $75(6.0)$ & $1.03(0.69-1.55)$ \\
\hline \multicolumn{4}{|l|}{ Former } \\
\hline No exposure to SHS & $1,752(10.0)$ & $156(8.7)$ & $1.01(0.72-1.41)$ \\
\hline SHS at home only & $68(0.5)$ & $14(0.7)$ & $1.27(0.56-2.88)$ \\
\hline SHS at workplace only & $907(7.3)$ & $84(6.5)$ & $1.17(0.79-1.71)$ \\
\hline SHS at both home and workplace & $51(0.5)$ & $3(0.3)$ & $0.59(0.16-2.16)$ \\
\hline \multicolumn{4}{|l|}{ Never } \\
\hline No exposure to SHS & $1,409(10.6)$ & $123(8.1)$ & 1.00 (ref) \\
\hline SHS at home only & $102(1.0)$ & $10(1.0)$ & $1.10(0.46-2.65)$ \\
\hline SHS at workplace only & $889(7.6)$ & $85(5.7)$ & $1.12(0.76-1.64)$ \\
\hline SHS at both home and workplace & $96(1.0)$ & $11(1.3)$ & $2.05(0.83-5.10)$ \\
\hline \multicolumn{4}{|l|}{ Women } \\
\hline \multicolumn{4}{|l|}{ Smoking status } \\
\hline \multicolumn{4}{|l|}{ Current } \\
\hline No exposure to SHS & $630(4.2)$ & $217(6.4)$ & $1.25(1.00-1.56)$ \\
\hline SHS at home only & $283(2.0)$ & $131(4.4)$ & $1.43(1.04-1.96)$ \\
\hline SHS at workplace only & $214(1.7)$ & $68(2.4)$ & $1.26(0.87-1.83)$ \\
\hline SHS at both home and workplace & $142(1.1)$ & $56(2.2)$ & $1.57(0.96-2.55)$ \\
\hline \multicolumn{4}{|l|}{ Former } \\
\hline No exposure to SHS & $283(2.0)$ & $70(2.3)$ & $1.04(0.72-1.51)$ \\
\hline SHS at home only & $50(0.4)$ & $17(0.9)$ & $2.32(1.04-5.16)$ \\
\hline SHS at workplace only & $71(0.6)$ & $22(1.0)$ & $1.60(0.82-3.13)$ \\
\hline SHS at both home and workplace & $22(0.2)$ & $6(0.3)$ & $1.73(0.53-5.62)$ \\
\hline \multicolumn{4}{|l|}{ Never } \\
\hline No exposure to SHS & $9,932(56.4)$ & $1,985(48.8)$ & 1.00 (ref) \\
\hline SHS at home only & $1,782(12.0)$ & $459(14.4)$ & $1.25(1.08-1.43)$ \\
\hline SHS at workplace only & $1,993(13.3)$ & $373(11.0)$ & $0.99(0.84-1.17)$ \\
\hline SHS at both home and workplace & $805(6.0)$ & $191(5.9)$ & $1.12(0.99-1.40)$ \\
\hline
\end{tabular}

${ }^{a}$ Adjusted for age, marital status, education, employment status, self-reported stress, self-rated health, alcohol dependence (AUDIT) and past diagnosis of depression by physicians

However, our study showed a significant OR only for women. Several other studies support our finding that women are more susceptible to SHS related factors [36] and associations between smoking and depression were more prominent in women [37]. This may be due to men's higher rate of smoking, which contributes to women's greater exposure to SHS at home [38, 39]. In our study, the most notable association was found for women who were exposed to SHS at home; there was a significant trend in the dose-response relationship between SHS and depressive symptoms compared to the SHS exposure at workplace. Another possible explanation is that many 
Table 3 Association between secondhand smoking and depression with different exposure duration

\begin{tabular}{|c|c|c|c|c|}
\hline \multirow[t]{2}{*}{ Characteristics } & \multicolumn{2}{|l|}{ Male } & \multicolumn{2}{|l|}{ Female } \\
\hline & Case N (weighted \%) & $\mathrm{OR}^{\mathrm{a}}(95 \% \mathrm{Cl})$ & Case $N$ (weighted \%) & $\mathrm{OR}^{\mathrm{a}}(95 \% \mathrm{Cl})$ \\
\hline \multicolumn{5}{|c|}{ Workplace exposure $(N=$ men 14,766 , women 19,804$)$} \\
\hline No exposure & $859(54.8)$ & 1.00 (ref) & $2,879(77.2)$ & 1.00 (ref) \\
\hline$<1$ hour/day & $389(29.4)$ & $0.92(0.77-1.09)$ & $470(14.0)$ & $0.89(0.76-1.04)$ \\
\hline \multirow[t]{2}{*}{$\geq 1$ hour/day } & $208(15.8)$ & $1.23(0.97-1.54)$ & $246(8.8)$ & $1.32(1.06-1.64)$ \\
\hline & $p$-trend & 0.256 & $p$-trend & 0.159 \\
\hline \multicolumn{5}{|c|}{ Home exposure $(N=$ men 14,846 , women 20,194$)$} \\
\hline No exposure & $1,359(91.5)$ & 1.00 (ref) & 2,896 (75.4) & 1.00 (ref) \\
\hline$<1$ hour/day & $81(6.6)$ & $0.90(0.65-1.23)$ & $2,083(17.1)$ & $1.18(1.02-1.35)$ \\
\hline \multirow[t]{2}{*}{$\geq 1$ hour/day } & $24(2.0)$ & $1.21(0.69-2.13)$ & $215(7.5)$ & $1.71(1.34-2.18)$ \\
\hline & $p$-trend & 0.977 & $p$-trend & $<0.001$ \\
\hline
\end{tabular}

${ }^{a}$ Adjusted for age, marital status, education, employment status, self-reported stress, self-rated health, alcohol dependence (AUDIT) and past diagnosis of depression by physicians

people are exposed to SHS, especially in more stressful job or home environments. In our data, women who reported severe stress levels were more likely to be exposed to SHS at both home and the workplace. In addition, women who were current or never smokers and exposed to SHS at home were more likely to report severe stress levels (Additional file 1: Table S1). Because stress is a wellknown cause of depression [40], SHS is also linked with depression. One study showed that there are correlations between banning smoking in the home and lowering the risk of depression [41].

In a meta-analysis of 85 cross-sectional studies [42], a significantly increased prevalence of depression was found in current smokers compared to those who had never smoked (OR 1.50, 95 \% CI 1.39-1.60). The magnitude of the increase in OR is very similar to our result. One study conducted in Korea showed a two-fold increased risk of depression in women who smoked compared to non-smoking women (OR 2.07, $95 \%$ CI 1.51-2.83) [43]. In addition, a community health study in Korea suggested that smoking is particularly associated with depression in women [35]. Nevertheless, there are some contradicting results. Studies conducted with African Americans failed to find any harmful physical effects of cigarette smoking on major adulthood depressive disorders $[44,45]$.

Interestingly, in our study, the likelihood of depressive symptoms in both current smokers and former female smokers was similar. In contrast, current smokers, including smokers who recently started smoking, showed significantly more depressive symptoms than recent former smokers in a study of Flemish women [46]. Furthermore, in one study conducted in Canada, current smoking rather than ever smoking was a major factor in the onset of depression [47]. However, in a study conducted in a Japanese workplace, the prevalence of depression was higher among past female smokers than current female smokers. The researchers suggested that this result might be caused by Japanese women's lower haemoglobin carbon monoxide binding capacity [48]. It is possible that the total amount of smoking was similar in current and former female smokers in our current study.

Several mechanisms could explain the relationship between smoking and depression [49]. One explanation, which is referred to as 'self-medication', assumes that smokers tend to smoke more to deal with depressive symptoms [50]. This hypothesis supports reverse causality in the association between smoking and depression. In our study, there was significant association between SHS and depression in women. This finding is concordant with the result of the study conducted on one birth cohort [13].

It is known that smoking affects dopamine levels in the human brain [51]. In active smokers, nicotine addiction causes dysregulation of the dopaminergic system, which affects vulnerability to depression [52]. An animal study also suggested that there was a certain effect of SHS on the dopamine system of rats [53]. In addition, free radicals generated by smoking tobacco cause oxidative stress, which damages tissues through protein oxidation and lipid peroxidation [54].

It is well known that there is a strong association between smoking and low socio-economic status [55] and that low socio-economic status is also related to exposure to SHS, especially among women. One U.S. study showed that adult women with manual working jobs and shorter educational attainment were more likely to be exposed in SHS in the home [56]. Another study showed that as white and African American women's 
socio-economic status decreased, they reported fewer home smoking bans [57]. In our study, although we adjusted for factors such as marital status, education and employment status, it is still possible that these factors, rather than SHS alone, contributed to the onset of depression symptoms.

This study has certain strengths. The study was conducted using a nationwide surveillance database that is representative of the entire South Korean population. In addition, this study focused not only on the smoking status of the participants but also on detailed information about the source of exposure to SHS. This made it possible to explain certain factors that might affect the association between SHS and depressive symptoms.

However, there are several limitations when interpreting the results of this study. First, KNHANES is a crosssectional survey; therefore the temporal relationship between exposure and outcome is uncertain. In this study, the time sequence between active smoking and depressive symptoms is unclear. Second, exposure to smoking was self-reported. Urine cotinine can be used as an appropriate biomarker to more accurately test environmental smoking exposure. Although urine cotinine was measured in KNHANES, the information was limited to only a small proportion of participants. We did not have a sufficiently large sample size for further analysis. The proportion of women who were confirmed as smokers using urine cotinine analysis was found to be $8.0 \%$ higher than that of women who self-reported as smokers in KNHANES [58]; therefore, we might have underestimated the association between smoking and depressive symptoms. Additionally, exposure to SHS might be underreported, as one study conducted in the U.S. reported a higher prevalence of SHS using serum cotinine than was self-reported [59]. Likewise, it was impossible to calculate the total number of packs smoked per year among the current smokers because of a lack of information in the KNHANES database. Lastly, participants self-reported their depressive symptoms by answering a simple question; a more standardized assessment tool such as the CES-D or the PHQ-9 must be used in further studies.

\section{Conclusions}

In conclusion, women who are current, former or never smokers with exposure to SHS at home have a higher likelihood of experiencing depressive symptoms. Following the enactment of the National Health Promotion Act in Korea in 1995, many public areas such as government buildings, large restaurants, public parks, streets and bus stations were designated as non-smoking areas. However, areas such as pubs and bars have not enforced smoke-free policies. Therefore, this study's findings that all types of smoking, including involuntary smoking, are associated with depression have implications for these establishments.

\section{Additional file}

Additional file 1: Distribution of stress level by smoking status. (DOCX $16 \mathrm{~kb})$

Competing interests

The authors declared that they have no competing interests.

\section{Authors' contributions}

Sun Jae Jung (SJ), Aesun Shin (AS) and Daehee Kang (DK) set conception and design of the study. AS and DK helped the acquisition of data. SJJ and AS made the draft of the manuscript. DK reviewed the manuscript and revised critical point with $S J J$, and AS. All authors read and approved the final manuscript.

\section{Acknowledgements}

This work was supported by Basic Research Fellowship Program from Seoul National University College of Medicine and a grant from Seoul National University Hospital (2015).

\section{Fundings}

We thank BK21 plus program through the National Research Foundation (NRF) funded by the Ministry of Education of Korea for financial support.

\section{Author details}

'Department of Biomedical Science, Seoul National University College of Medicine, Seoul, South Korea. ${ }^{2}$ Department of Preventive Medicine, Seoul National University College of Medicine, Seoul, South Korea. ${ }^{3}$ Cancer Research Institute, Seoul National University Hospital, Seoul, South Korea.

Received: 16 February 2015 Accepted: 8 October 2015

Published online: 14 October 2015

\section{References}

1. Jee SH, Lee JK, Kim IS. Smoking-attributable mortality among Korean adults: 1981-2003. Korean J Epidemiol. 2006;28(1):92-9.

2. Heo S, Lee JT. Disease burdens from environmental tobacco smoke in Korean adults. Int J Environ Health Res. 2015;25(3):330-48.

3. Lee $\mathrm{S}$, The tobacco industry in South Korea since market liberalisation. The tobacco industry in South Korea since market liberalisation:implications for strengthening tobacco contro. UK: London School of Hygiene \& Tropical Medicine; 2011.

4. OECD/World health Oganization. Health at a Glance: Asia/Pacific 2014: Measuring Progress towards Universal Health Coverage. Paris, France: OECD Publishing; 2014

5. Callinan JE, Clarke A, Doherty K, Kelleher C. Legislative smoking bans for reducing secondhand smoke exposure, smoking prevalence and tobacco consumption. Cochrane Database Syst Rev. 2010;4, CD005992.

6. Korea ministry of health and welfare. International Tobacco Control policy evaluation project (2005-2010)-Korea report. In. Edited by Korean Ministry of Health and Welfare. Seoul: Korea ministry of health \& welfare; 2012

7. Korean Center for Disease and Control. The fourth Korea National Health and Nutrition Examinatio Survey. In. Edited by Korean Ministry of Health and Welfare. Korean Center for Disease and Control publishing. Seoul; 2008.

8. Seo MK. Women's smoking behavior and its implications. Health Welf Policy Forum. 2009;152:73-82.

9. Choi S. Trends of smoking status in South Korea. In: Public Health Weekly Report. vol. 7: Korea Center for Disease Control (KCDC); 2014: 478-480.

10. Ayers JW, Hofstetter CR, Hughes SC, Park H, Paik HY, Irvin VL, et al. Smoking on both sides of the pacific: home smoking restrictions and secondhand smoke exposure among Korean adults and children in Seoul and California. Nicotine Tob Res. 2010;12(11):1142-50.

11. Hawkins SS, Chandra A, Berkman L. The impact of tobacco control policies on disparities in children's secondhand smoke exposure: a comparison of methods. Matern Child Health J. 2012;16 Suppl 1:S70-7.

12. Mills AL, White MM, Pierce JP, Messer K. Home smoking bans among U.S. households with children and smokers. Opportunities for intervention. Am J Prev Med. 2011;41(6):559-65. 
13. Boden JM, Fergusson DM, Horwood LJ. Cigarette smoking and depression: tests of causal linkages using a longitudinal birth cohort. Br J Psychiatry. 2010;196(6):440-6.

14. Flensborg-Madsen $T$, von Scholten MB, Flachs EM, Mortensen EL, Prescott E, Tolstrup JS. Tobacco smoking as a risk factor for depression. A 26-year population-based follow-up study. J Psychiatr Res. 2011;45(2):143-9.

15. Hamer M, Stamatakis E, Batty GD. Objectively assessed secondhand smoke exposure and mental health in adults: cross-sectional and prospective evidence from the Scottish Health Survey. Arch Gen Psychiatry. 2010;67(8):850-5.

16. Lam E, Kvaavik E, Hamer M, Batty GD. Association of secondhand smoke exposure with mental health in men and women: cross-sectional and prospective analyses using the U.K. Health and Lifestyle Survey. Eur Psychiatry. 2013;28(5):276-81.

17. Cho MJ, Nam JJ, Suh GH. Prevalence of symptoms of depression in a nationwide sample of Korean adults. Psychiatry Res. 1998;81(3):341-52.

18. Kim E. Multidimensional acculturation attitudes and depressive symptoms in Korean Americans. Issues Ment Health Nurs. 2009;30(2):98-103.

19. Jang Y, Chiriboga DA, Kim G, Cho S. Changes in perceived health and depressive symptoms: a longitudinal analysis with older Korean Americans. J Immigr Minor Health. 2009;11(1):7-12.

20. Riolo SA, Nguyen TA, Greden JF, King CA. Prevalence of depression by race/ ethnicity: findings from the National Health and Nutrition Examination Survey III. Am J Public Health. 2005;95(6):998-1000.

21. Weissman MM, Leaf PJ, Tischler GL, Blazer DG, Karno M, Bruce ML, et al. Affective disorders in five United States communities. Psychol Med. 1988;18(1):141-53.

22. Kessler RC. Epidemiology of women and depression. J Affect Disord. 2003;74(1):5-13.

23. Nakata A, Takahashi M, Ikeda T, Hojou M, Nigam JA, Swanson NG. Active and passive smoking and depression among Japanese workers. Prev Med. 2008;46(5):451-6.

24. Kessler RC, Berglund P, Demler O, Jin R, Koretz D, Merikangas KR, et al. The epidemiology of major depressive disorder: results from the National Comorbidity Survey Replication (NCS-R). JAMA. 2003;289(23):3095-105.

25. Luk JW, Tsoh JY. Moderation of gender on smoking and depression in Chinese Americans. Addict Behav. 2010;35(11):1040-3.

26. King BA, Mirza SA, Babb SD, Group GC. A cross-country comparison of secondhand smoke exposure among adults: findings from the Global Adult Tobacco Survey (GATS). Tob Control. 2013;22(4), e5.

27. Bandiera FC, Arheart KL, Caban-Martinez AJ, Fleming LE, McCollister K, Dietz NA, et al. Secondhand smoke exposure and depressive symptoms. Psychosom Med. 2010;72(1):68-72

28. Kweon S, Kim Y, Jang MJ, Kim Y, Kim K, Choi S, et al. Data resource profile: the Korea National Health and Nutrition Examination Survey (KNHANES). Int J Epidemiol. 2014;43(1):69-77.

29. Kim J, Jo I. Age-dependent association between sleep duration and hypertension in the adult Korean population. Am J Hypertens. 2010;23(12):1286-91.

30. Park SJ, Jeon HJ, Kim JY, Kim S, Roh S. Sociodemographic factors associated with the use of mental health services in depressed adults: results from the Korea National Health and Nutrition Examination Survey (KNHANES). BMC Health Serv Res. 2014;14:645.

31. Barbor TF, Higgins-Biddle JC, Saunders JB, Monteiro MG. AUDIT-The Alcohol Use Disorders Identification Test: Guidelines for Use in Primary Care. Secondth ed. Geneva: World Health Organization; 2001.

32. Anuurad E, Shiwaku K, Nogi A, Kitajima K, Enkhmaa B, Shimono K, et al. The new BMI criteria for asians by the regional office for the western pacific region of WHO are suitable for screening of overweight to prevent metabolic syndrome in elder Japanese workers. J Occup Health. 2003;45(6):335-43.

33. Lee KJ. Current smoking and secondhand smoke exposure and depression among Korean adolescents: analysis of a national cross-sectional survey. BMJ open. 2014;4(2), e003734

34. Taha F, Goodwin RD. Secondhand smoke exposure across the life course and the risk of adult-onset depression and anxiety disorder. J Affect Disord. 2014;168:367-72.

35. Yun WJ, Shin MH, Kweon SS, Ryu SY, Rhee JA. Association of smoking status, cumulative smoking, duration of smoking cessation, age of starting smoking, and depression in Korean adults. BMC Public Health. 2012;12:724.
36. Schoj V, Allemandi L, lanovsky O, Lago M, Alderete M. Smoke-free environments: age, sex, and educational disparity in 25 Argentinean cities. Cancer Causes Control. 2012;23(10):1607-14.

37. Husky MM, Mazure CM, Paliwal P, McKee SA. Gender differences in the comorbidity of smoking behavior and major depression. Drug Alcohol Depend. 2008:93(1-2):176-9.

38. Greaves LJ, Hemsing NJ. Sex, gender, and secondhand smoke policies: implications for disadvantaged women. Am J Prev Med. 2009;37(2 Suppl):S131-7.

39. Robinson J, Ritchie D, Amos A, Cunningham-Burley S, Greaves L, Martin C. 'Waiting until they got home': gender, smoking and tobacco exposure in households in Scotland. Soc Sci Med. 2010;71(5):884-90.

40. Hammen C. Stress and depression. Annu Rev Clin Psychol. 2005:1:293-319.

41. Breslau N, Peterson EL, Schultz LR, Chilcoat HD, Andreski P. Major depression and stages of smoking. A longitudinal investigation. Arch Gen Psychiatry. 1998;55(2):161-6.

42. Luger TM, Suls J, Vander Weg MW. How robust is the association between smoking and depression in adults? A meta-analysis using linear mixedeffects models. Addict Behav. 2014;39(10):1418-29.

43. Noh JW, Juon HS, Lee S, Kwon YD. Atypical Epidemiologic Finding in Association between Depression and Alcohol Use or Smoking in Korean Male: Korean Longitudinal Study of Aging. Psychiatry invest. 2014;11(3): 272-80.

44. Klonoff EA, Landrine $\mathrm{H}$. Depressive Symptoms and Smoking among US Black Adults: Absence of a Relationship. J Health Psychol. 2001;6(6): 645-9.

45. Strong C, Juon HS, Ensminger ME. Long-term effects of adolescent smoking on depression and socioeconomic status in adulthood in an urban African American cohort. J Urban Health. 2014:91(3):526-40.

46. De Wilde KS, Trommelmans LC, Laevens HH, Maes LR, Temmerman M, Boudrez HL. Smoking patterns, depression, and sociodemographic variables among Flemish women during pregnancy and the postpartum period. Nurs Res. 2013;62(6):394-404.

47. Khaled SM, Bulloch AG, Williams JV, Hill JC, Lavorato DH, Patten SB. Persistent heavy smoking as risk factor for major depression (MD) incidence-evidence from a longitudinal Canadian cohort of the National Population Health Survey. J Psychiatr Res. 2012:46(4):436-43.

48. Takeuchi T, Nakao M, Yano E. Relationship between smoking and major depression in a Japanese workplace. J Occup Health. 2004;46(6):489-92.

49. Bandiera FC. What are candidate biobehavioral mechanisms underlying the association between secondhand smoke exposure and mental health? Med Hypotheses. 2011;77(6):1009-10.

50. Degenhardt $L$, Hall W. The relationship between tobacco use, substance-use disorders and mental health: results from the National Survey of Mental Health and Well-being. Nicotine Tob Res. 2001;3(3):225-34.

51. Le Foll B, Guranda M, Wilson AA, Houle S, Rusjan PM, Wing VC, et al. Elevation of dopamine induced by cigarette smoking: novel insights from a [11C] - + - PHNO PET study in humans. Neuropsychopharmacology. 2014;39(2):415-24.

52. Malhi GS, Berk M. Does dopamine dysfunction drive depression? Acta Psychiatr Scand Suppl. 2007:433:116-24.

53. Bahk JY, Li S, Park MS, Kim MO. Dopamine D1 and D2 receptor mRNA up-regulation in the caudate-putamen and nucleus accumbens of rat brains by smoking. Prog Neuropsychopharmacol Biol Psychiatry. 2002;26(6):1095-104

54. Ozguner F, Koyu A, Cesur G. Active smoking causes oxidative stress and decreases blood melatonin levels. Toxicol Ind Health. 2005;21(1-2):21-6.

55. Center for Disease Control and Prevention. Cigarette Smoking Among Adults-United States, 2007. In. Edited by Morbidity and Morality Weekly Report (MMWR). Atlanta U.S.: MMWR publications; 2008:1221-1226.

56. Shopland DR, Anderson CM, Burns DM. Association between home smoking restrictions and changes in smoking behaviour among employed women. J Epidemiol Community Health. 2006;60 Suppl 2:44-50.

57. Shavers VL, Fagan P, Alexander LA, Clayton R, Doucet J, Baezconde-Garbanati L. Workplace and home smoking restrictions and racial/ethnic variation in the prevalence and intensity of current cigarette smoking among women by poverty status, TUS-CPS 1998-1999 and 2001-2002. J Epidemiol Community Health. 2006;60 Suppl 2:34-43. 
58. Jung-Choi KH, Khang YH, Cho HJ. Hidden female smokers in Asia: a comparison of self-reported with cotinine-verified smoking prevalence rates in representative national data from an Asian population. Tob Control. 2012;21(6):536-42.

59. Max W, Sung HY, Shi YL. Who Is Exposed to Secondhand Smoke? SelfReported and Serum Cotinine Measured Exposure in the US, 1999-2006. Int J Env Res Pub He. 2009;6(5):1633-48.

Submit your next manuscript to BioMed Central and take full advantage of:

- Convenient online submission

- Thorough peer review

- No space constraints or color figure charges

- Immediate publication on acceptance

- Inclusion in PubMed, CAS, Scopus and Google Scholar

- Research which is freely available for redistribution 